\title{
A Novel Approach to Determine the Astronomical Vessel Position
}

\section{Chih-Li Chen}

Doctor Candidate, Institute of Civil Engineering, National Taiwan University, 1, Sec. 4, Roosevelt Road, Taipei, Taiwan 10617, R.O.C.

Tien-Pen Hsu

Associate Professor, Institute of Civil Engineering, National Taiwan University, 1, Sec. 4, Roosevelt Road, Taipei, Taiwan 10617, R.O.C

Jiang-Ren Chang

Associate Professor, Department of System Engineering and Naval Architecture, National Taiwan Ocean University, 2, Pei-Ning Road, Keelung, Taiwan 202, R.O.C., cjr@sena.ntou.edu.tw

Follow this and additional works at: https://jmstt.ntou.edu.tw/journal

Part of the Civil and Environmental Engineering Commons

\section{Recommended Citation}

Chen, Chih-Li; Hsu, Tien-Pen; and Chang, Jiang-Ren (2003) "A Novel Approach to Determine the Astronomical Vessel Position," Journal of Marine Science and Technology. Vol. 11: Iss. 4, Article 6.

DOI: $10.51400 / 2709-6998.2293$

Available at: https://jmstt.ntou.edu.tw/journal/vol11/iss4/6

This Research Article is brought to you for free and open access by Journal of Marine Science and Technology. It has been accepted for inclusion in Journal of Marine Science and Technology by an authorized editor of Journal of Marine Science and Technology. 


\title{
A NOVEL APPROACH TO DETERMINE THE ASTRONOMICAL VESSEL POSITION
}

\author{
Chih-Li Chen* Tien-Pen Hsu** and Jiang-Ren Chang***
}

Key words: astronomical vessel position, celestial navigation, trigonometric equation, SEEM.

\begin{abstract}
In this paper, a novel approach based on the trigonometric equation solving technique is developed to solve the classical problem of celestial navigation. It is shown that this approach, namely, the simultaneous equal-altitude equations method (SEEM), can directly calculate the astronomical vessel position (AVP) without an additional graphical procedure. It is also found that the SEEM is not only simpler than the matrix method but is also more straightforward as compared with the spherical triangle method. In addition, aimed at the drawbacks of the intercept method, an improved approach with the new computation procedure is presented to plot the celestial line of position without the intercept. With the improved approach and iteration method the AVP can be determined successfully. The improved approach then, is used to validate the SEEM through two designed examples. Numerical results show that both the SEEM and the improved approach are more accurate and effective as compared with the conventional intercept method.
\end{abstract}

\section{INTRODUCTION}

It is known that celestial navigation is the process of determining the vessel position by observing the celestial bodies, such as the sun, moon, planets, and stars. Only after the longitude and latitude of a vessel at sea have been accurately calculated, the navigator can thus, determine the safe course for the vessel and its economical route. Before the development of a means of determining accurate time at sea, longitude could not be found by celestial observation. However, celestial bodies, whose positions are independent of the time,

Paper Submitted 10/10/03, Accepted 11/24/03. Author for Correspondence: Jiang-Ren Chang.

*Doctor Candidate, Institute of Civil Engineering, National Taiwan University, 1, Sec. 4, Roosevelt Road, Taipei, Taiwan 10617, R.O.C.

**Associate Professor, Institute of Civil Engineering, National Taiwan University, 1, Sec. 4, Roosevelt Road, Taipei, Taiwan 10617, R.O.C.

***Associate Professor, Department of System Engineering and Naval Architecture, National Taiwan Ocean University, 2, Pei-Ning Road, Keelung, Taiwan 202, R.O.C. E-mail: cjr@sena.ntou.edu.tw were used to determine the latitude and served as an indication of direction in a very general way. The development of the marine chronometer, which is innovated by John Harrison [15], opened up a whole new vista to the navigator. Several methods began to appear to utilize this new dimension of navigation. During the two centuries, lots of efforts have been made to provide easier or more adequate methods of reducing observations to a form of suitable for determining the position.

To date, the sight reduction methods, which include the high-altitude observation and intercept method, are widely used in maritime training education or practical operation [8]. From theoretical point of view, the concept of celestial line of position (LOP) is originated from the circle of equal altitude, that is, the center of this circle should be the geographical position (GP) of the celestial body and the radius is equal to the co-altitude. The celestial circle of position (COP) can be directly plotted on the navigational chart. However, there are two reasons why this direct method of plotting the COP is not suitable for most of celestial observations. The first is that the radii of most circles of equal altitude are too long to be plotted on the chart. Secondly, graphic distortion at the high latitude is apparent on the commonly used Mercator chart, and the distortion increases with the latitude of the GP. These causes lead to the limited usage of high-altitude observations. For instance, the high-altitude observation is only available at the observed altitude greater than 87 degrees [2,11]. If, however, the celestial body is very high in altitude, the co-altitude will be small enough to plot on a navigational chart, and the distortion is negligible. That is why all sights with an observed altitude of 87 degrees or more are classified into high-altitude observations, and the resulting COP is directly plotted.

However, most of the altitudes of celestial bodies are smaller than 87 degrees, to break through the limitation of high-altitude observations, Commander Marcq de St.- Hilaire of the French Navy first introduced the assumed position (AP) to form the altitude difference, or the intercept method, which has become the basis of virtually all present day celestial navigation [2, 11]. 
Following with the intercept method, numerous ingenious solutions to the problem of celestial navigation have been devised and reduced to the practice. It should be noted that available solutions to this problem are essentially trial-and-error methods using the concept of the AP [16]. Besides, these solution methods, no matter directly or indirectly for their calculating procedures, are inevitably driven into the graphical procedure for the LOP [2, 5].

To resolve the problems mentioned above, let's go back to the "initial point" and consider the concept of the circle of equal altitude. Basically, two circles of different celestial bodies will result in two intersections and one of them will be the AVP by judging either the dead reckoning (DR) position or estimated position (EP). Since some errors will exist due to observation for the celestial fix principle of circle of equal altitude, three circles may arise three possible AVPs, and four circles may produce six possible positions, etc. Therefore, a case of three circles or more will become an over-determined problem of the AVP. Such a problem usually can be solved by using the least mean squares technique $[6,13,14]$. Basically, the classical problem of celestial navigation, in its simplest form, is the determination of an AVP of two celestial bodies, observed at known Greenwich Mean Time (GMT) on a known date [16]. With fast developments of the computers, the direct numerical computation becomes possible, and several packages, based on the numerical schemes, such as the STELLA by the US navy and the ASTROLAB by the France, have been developed [2, 13]. The direct computation methods, in our opinion, they can be categorized into the spherical triangle method and the matrix one. Although the former is usually called the direct method due to its practice, its solving process is still indirect. In contrast, the latter is a direct one owing to its mathematical formulation. For the matrix method, however, a four-order equation is formulated by using the plane analytic geometry, and it needs to be implemented by the numerical program for the AVP [16]. The drawbacks of the mentioned methods motivate this research to develop a simple and direct approach called simultaneous equal-altitude equations method (SEEM).

Aimed at simplicity, the SEEM is formulated to determine the AVP based on the trigonometric equation solving technique, which owns the respective advantages of the spherical triangle method and the matrix one. The SEEM, unlike the spherical triangle method that needs lots of trigonometric equations in solving process, only adopts two equations to obtain the AVP. Besides, when the SEEM is compared with the matrix method, it shows that their formulations are similar each other; however, the SEEM adopts the local meridian in place of the Greenwich meridian to form a relative meridian concept and simplify the constructed equations. In summary, the SEEM is not only more straightforward than the spherical triangle method but also simpler than the matrix one with respect to the solving procedures.

To reduce drawbacks of the intercept method, an improved approach and its computation procedure is also developed for solving the LOP especially when the condition of altitude of a single celestial body is encountered. This approach shows the merit of plotting the LOP without intercept since it can directly calculate the perpendicular intersection of computed azimuth arc and observed altitude arc. By using the improved approach, the navigators can easily plot the LOP on the chart. With information of altitudes of two celestial bodies, a combined use of the approach and the iteration method, which is used to minimize the error of artificial AP selection, can further determine the AVP effectively. Results from the iteration methods for the numerical example show the effectiveness of the improved approach, and results of the proposed approach are further used to validate the SEEM.

This paper, apart from the current section is organized as follows. Section 2 details methodologies of the intercept method and reviews theoretical backgrounds of these direct computation methods. Derivations of needed equations, constructions of the computation procedures of the SEEM and the improved approach are presented in Section 3. Two available examples $[2,11]$ are adopted for validating the proposed approaches and included in Section 4. Finally, some important conclusions are drawn in Section 5.

\section{REVIEWS ON THE METHOLODGY FOR DETERMINING ASTRONOMICAL VESSEL POSITION}

The theory of the sight reduction method is interpreted in this section first. Various calculating methods, which can be categorized as the intercept method and are used when the computer technology or the calculator was not well developed, will be reviewed also. And several direct computation methods for determining the AVP will be introduced since the SEEM combines the advantages of these methods and avoids the shortcomings of them.

\section{Theory of sight reduction method}

The basic concept of the sight reduction method, which is defined as the process of deriving from a celestial observation the information needed for establishing a LOP, is attributed to the circle of equal altitude. The observation itself consists of measuring the altitude of a celestial body and noting the time. In general, there 
exist two approaches for sight reduction, that is, the high-altitude observation and the intercept method. For their solving processes, the former is a kind of direct graphical methods, while the latter is a kind of calculation methods with graphic procedures. The high-altitude observation is to plot the celestial COP, and the plotting elements are the GP of the celestial body and its co-altitude. The flowchart for solving the COP by using the high-altitude observation is shown in Fig.1. The intercept method, in contrast, is to plot the celestial LOP and the plotting elements are the AP, computed azimuth of the celestial body, $Z n$, and the intercept, $a$. The flowchart for solving the LOP by using the intercept method is shown in Fig. 2. It should be note that, in Figs. 1 and 2, the observed altitude $H_{o}$ can be determined by correcting the instrument errors (e.g., fixed and adjustable errors) and optical deviation errors (e.g., dip, refraction and parallax errors, etc.) from the sextant altitude, $h_{s}$. Besides, by using the nautical almanac or related software, position variables in the celestial equator coordinate system, such as the declination, Dec, and the Greenwich hour angle, GHA, can be obtained at observed time.

\section{Calculating methods based on the idea of intercept}

The basic idea of the intercept method is to choose an AP at the most nearby probable position (MPP) and

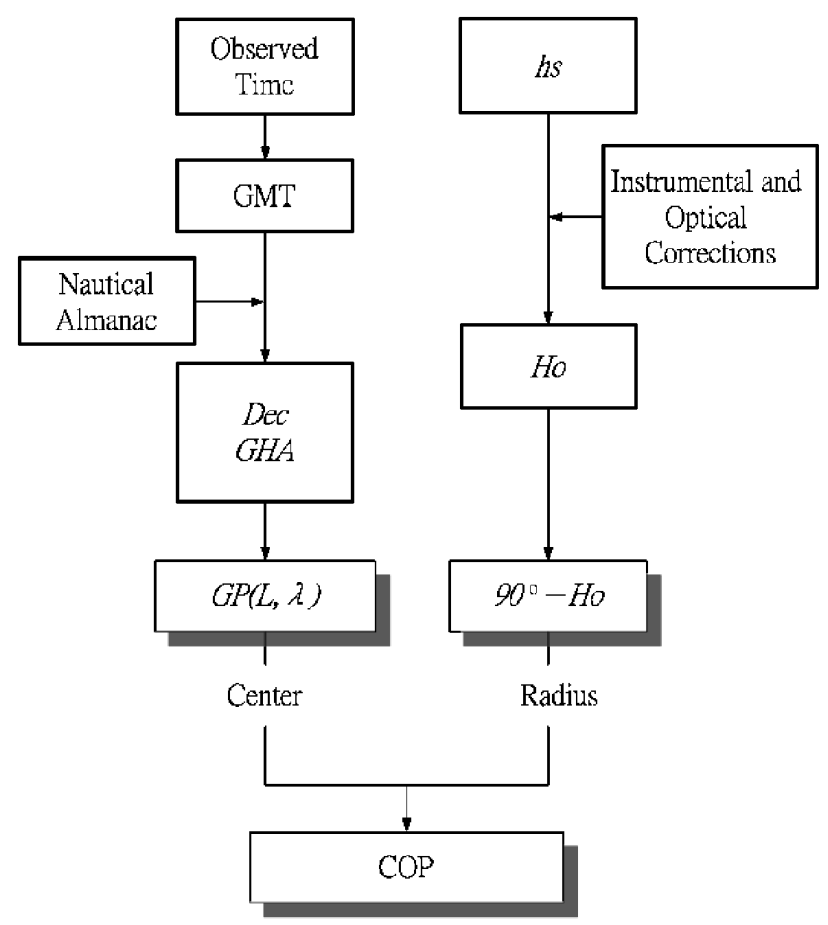

Fig. 1. The flowchart for solving the COP by using the high-altitude observation. take it as the reference position to calculate the altitude and azimuth. By comparing the computed altitude and observed altitude, the difference of the two altitudes (called the intercept or altitude difference, $a$ ) can be obtained. Therefore, once the AP, computed azimuth of the body, and intercept are all determined, the LOP can be plotted according to the three elements.

Obtaining the computed altitude and azimuth for the intercept method is an astronomical spherical triangle problem. That is, when the two sides and the included angle of an oblique spherical triangle are given, the problem is to solve the third side (co-altitude) and the outer angle (azimuth angle). Basically there are two kinds of methods to fix it $[2,5]$. One is called the direct method, in which the triangle is not divided, and the other is the indirect one, in which the triangle is divided into two right-angled spherical triangles. For the direct method, the computed formulae including the cosinehaversine equations, the classic equations and cosinefour parts equations can be selected respectively. For the indirect one, the basic concept is to divide the astronomical triangle into two right-angled spherical triangles due to easy application of the Napier's Rule,

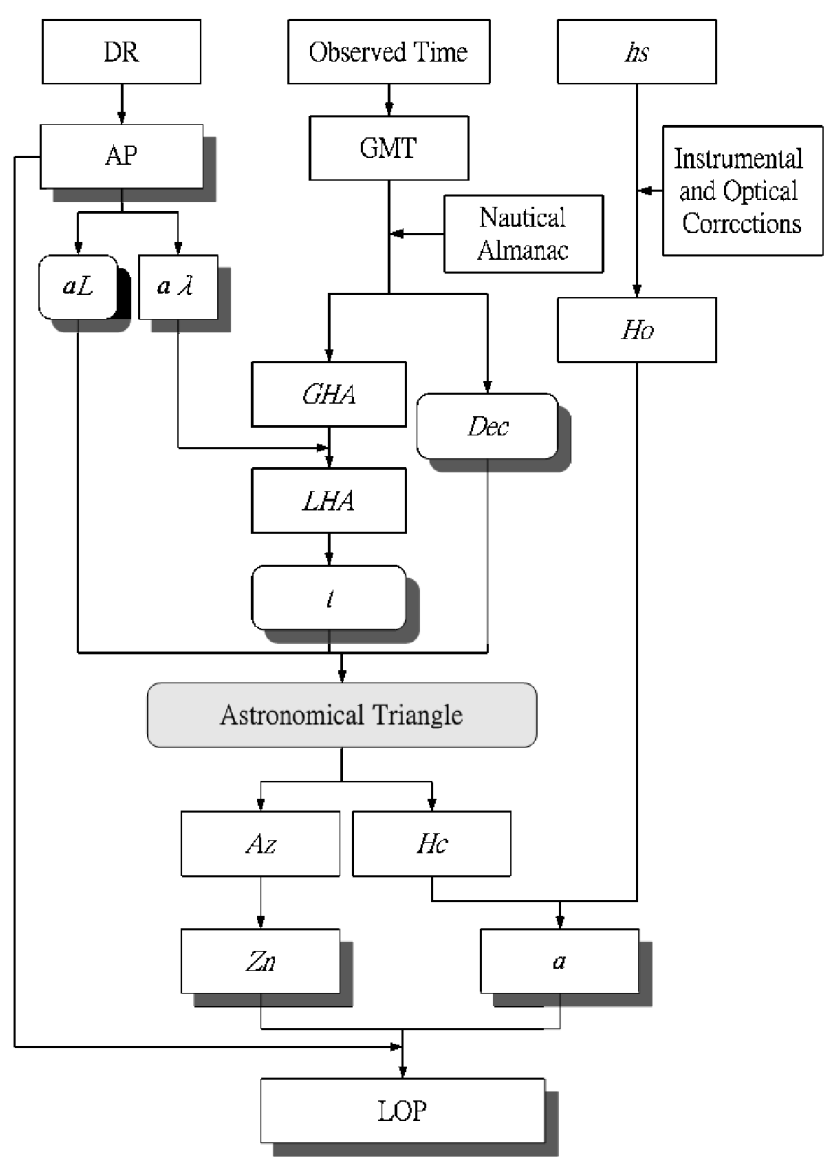

Fig. 2. The flowchart for solving the LOP by using the intercept method. 
and this method can be further categorized into two types. Type one is to drop arc of the great circle from the celestial body perpendicular to the celestial meridian, while type two is to drop arc of great circle from the zenith to the hour circle. Based on the two types of methodology, many researches were devoted to the field of the indirect method and resulted in many methods. In some methods, partial solutions were made, and the resulted were tabulated into short tables due to their simplicity and convenience, for instance, Aquino and Braga of Brazil; Ball, Comire, Davis, and Smart of England; Bertin and Hugon of France; Fuss of Germany; Ogura and Yonemura of Japan; Blackburne of New Zealand; Pinto of Portugal; Garcia of Spain; and Ageton, Driesonstok, Gingrich, Rust, and Weems of the United States $[2,5]$. Due to these short tables, the indirect method is usually called the short method. These short methods are still in use mainly due to the compactness of their tables and the universality of their applications. They are an intermediate step between the earlier tedious solutions and the fast tabulated ones, and they encouraged the navigator to work to a practical precision. The earlier custom of working to a precision not justified by the accuracy of the used information created a false sense of safety for navigators, especially those of beginners. Moreover, uses of logarithmic or auxiliary functions during calculating process may easily result in mistake.

Therefore, the inspection tables based on the direct method were proposed to improve the "shortcoming" of the short methods. As mentioned above, these inspection tables, like the Pub. No. 214, Pub. No. 249 and Pub. No. 229 in the references of [2, 11], are constructed by those available spherical triangle equations. That is, when the latitude, declination, and local hour angle are entering arguments, for instance like the Pub. No. 229, the altitude and azimuth calculated by the cosine-four parts equations are tabulated. Since the inspection tables offer additional detailed information and avoid possibility of calculation mistakes, they have now become the commonly used tools. However, detailed calculating information largely increases the amounts of these tables and leads to the inconvenience of carrying especially for the navigators of small vessels.

It should be emphasized that two basic assumptions are made in this ingenious intercept method. One is that the azimuth of the observed vessel position to the GP of a celestial body is the same as that of the AP to the GP. The other is that when the co-altitude is large enough, the COP can be considered as the LOP. Therefore, the precision of the AVP is influenced by these two basic assumptions. The reasons are described in the following.
(1) The distance between the AP and the true vessel position should not exceed 30 nautical miles due to entering arguments of integrated degrees; however, the true vessel position is unknown for the navigational practical work. Therefore, the intercept method is essentially a kind of trial-and-error method. That is, if after the observed vessel position had been obtained, and the distance between the observed position and the initial AP had exceeded 30 nautical miles, then the obtained observed vessel position could be considered as the new AP in the iterative calculation with graphic procedures for increasing the precision of AVP.

(2) When a celestial body is observed at a very high altitude, for instance, the altitude exceeds 70 degrees, in general, the co-altitude will be smaller and the curvature of the COP will be larger. Thus, the error of curvature due to the replacement of the COP as LOP on the Mercator chart will be increased.

\section{Comments on Direct Computation Methods}

Aimed at the classical problem of the celestial navigation, the direct computation methods for the AVP, can be categorized into the spherical triangle method and the matrix one. Comments on these two methods are given in this section since some solving techniques used in the SEEM are followed with both of them as mentioned in the previous section.

\section{A. Spherical triangle method}

Two centers of circles of equal altitude are given as $S_{1}$ and $S_{2}$, respectively, and their radii are $z d_{1}$ and $z d_{2}$, respectively. Now, assume the two intersections of the two circles of equal altitude be $P_{1}$ and $P_{2}$, respectively, and one of them is the AVP, $P$. Then, the elevated pole, $P_{n}, S_{1}$ and $S_{2}$ can form three arcs of the great circles on another as shown in Fig. 3. Therefore, the problem now becomes: the two zenith distances of two celestial bodies $\left(z d_{1}\right.$ and $\left.z d_{2}\right)$, the two pole distances of two celestial bodies $\left(p d_{1}\right.$ and $\left.p d_{2}\right)$, and the difference of hour angle between two celestial bodies (HA) are known and try to solve the AVP. The solving procedures using the spherical triangle method are summarized in the following (Refer to Fig. 3).

Step 1. For the spherical triangle $\bar{\Delta} P_{n r} S_{2} S_{1}$, if $p d_{1}, p d_{2}$ and $H A$ are known, then solve the great circle distance between two celestial bodies, $D$.

Step 2. For the spherical triangle $\bar{\Delta} P_{n r} S_{2} S_{1}$, if $p d_{1}, p d_{2}$ and $H A$ or $p d_{1}, p d_{2}$ and $D$ are known, then solve the angle $\alpha$.

Step 3. For the spherical triangle $\bar{\Delta} P_{1} S_{2} S_{1}$ or $\bar{\Delta} P_{2} S_{2} S_{1}$, if $z d_{1}, z d_{2}$ and $D$ are known, then solve the angle 


\section{$\beta$.}

Step 4. For the vessel position $P_{1}$ in the spherical triangle $\bar{\Delta} P_{n r} S_{2} P_{1}$, the difference of angles $m$ is equal to $(\alpha \sim \beta)$; while for the vessel position $P_{2}$ in the spherical triangle $\bar{\Delta} P_{n r} S_{2} P_{2}$, the sum of angles $M$ is equal to $(\alpha+\beta)$ in which $M$ and $\mathrm{m}$ are called the parallactic angle of the celestial body $S_{2}$.

Step 5. For the spherical triangle $\bar{\Delta} P_{n r} S_{2} P_{1}$ or $\bar{\Delta} P_{n r} S_{2} P_{2}$, if $p d_{2}, z d_{2}$ and $m$ (or $M$ ) are known, then solve the two latitudes of AVPs, $L_{P_{1}}$ and $L_{P_{2}}$.

Step 6. For the spherical angle $\bar{\Delta} P_{n r} S_{2} P_{1}$ or $\bar{\Delta} P_{n r} S_{2} P_{2}$, if $p d_{2}, z d_{2}$ and $m$ (or $M$ ) as well as $p d_{2}, z d_{2}$, and $L_{P_{1}}\left(\right.$ or $L_{P_{2}}$ ) are known, then solve the meridian angle of the celestial body $S_{2}$. Finally, the longitudes of AVPs, $\lambda_{P_{1}}$ and $\lambda_{P_{2}}$, can be obtained by the conversion of the meridian angle and the Greenwich hour angle of the celestial body $S_{2}$.

After clarifying the solving procedures of the spherical triangle method, one can easily understand Chiesa, Kotlaric and many other researchers' works are based on the spherical triangle methods. For instance, one can found that in Chiesa's work [4], those spherical triangle equations, such as the cosine formula for side, four parts formula, half angle formula, sine formula and Napier's analogies, are adopted in Steps 1, 2, 3, 5, and 6 , respectively. As for the work of Kotlaric $[9,10]$, transformation of the Haversine function, $\operatorname{Hav} x=\sin ^{2} \frac{x}{2}$, is adopted in Steps 1 and 5; the half angle formula $1 \mathrm{~s}$ adopted in Steps 2, 3, and 6. Other related papers can also be found in Ref. [1,12]. Further to analyze, except for Step 4, any one of the spherical triangle formulae used in Steps shows the relation of three sides and one angle. Therefore, without consideration of error propagation existing in Steps, the cosine formula

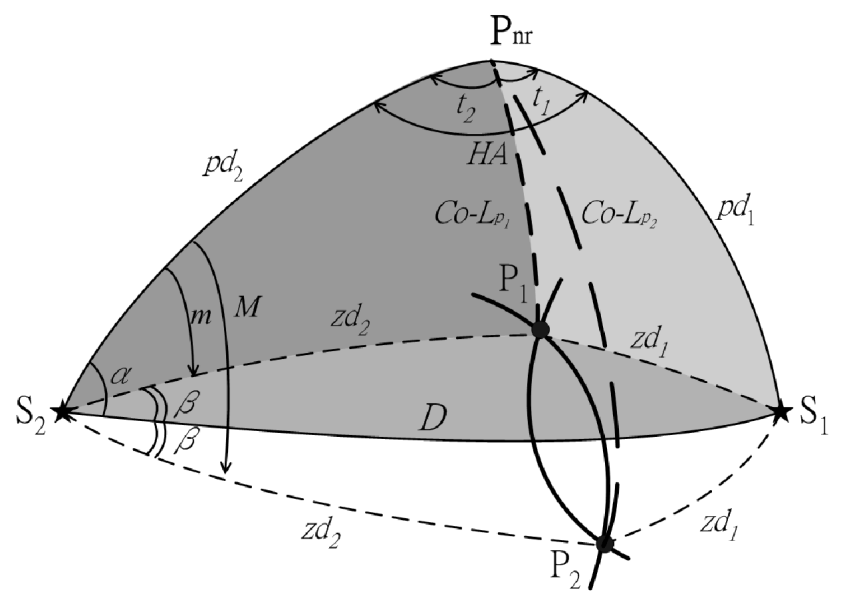

Fig. 3. An illustration of obtaining an astronomical vessel position by using the spherical triangle method. for side can be adopted in every step of the procedures. In summary, the trigonometric equations are adopted for the formulae of the spherical triangle method and for constructing the computing procedures as mentioned above, the spherical triangle method is actually an indirect solver.

\section{B. Matrix method}

The AVP of the Earth coordinate system in a Cartesian coordinate system can be expressed in a vector form as

$$
\vec{P}=(X, Y, Z)=(\cos L \cdot \cos \lambda, \cos L \cdot \sin \lambda, \sin L),
$$

in which $L$ denotes the latitude of an observer, and $\lambda$ denotes the longitude of an observer. Similarly, the celestial body position of the celestial equator coordinate system in a Cartesian coordinate system can be expressed as

$$
\vec{E}=(x, y, z)=(\cos d \cdot \cos G, \cos d \cdot \sin G, \sin d),
$$

in which $d$ denotes the declination of a celestial body, and $G$ denotes the Greenwich hour angle of a celestial body. Then, the included angle of the unit vectors, $\vec{P}$, and $\vec{E}$, is the observed co-altitude and the dot product of the two vectors yields

$$
\overrightarrow{\boldsymbol{E}} \cdot \overrightarrow{\boldsymbol{P}}=\cos \left(90^{\circ}-H\right)=\sin H=h,
$$

in which $H$ represents the observed altitude.

Now, assume the observed altitudes of the two celestial bodies are obtained simultaneously or nearly simultaneously and the AVP of the Earth coordinate system is the zenith of the celestial horizontal coordinate system. From the viewpoint of the observer, it means that the observed altitude of the zenith should be 90 degrees, therefore, the three expressions can be presented as

$$
\left[\begin{array}{ccc}
x_{1} & y_{1} z_{1} \\
x_{2} & y_{2} & z_{2} \\
X & Y & Z
\end{array}\right]\left[\begin{array}{c}
X \\
Y \\
Z
\end{array}\right]=\left[\begin{array}{c}
h_{1} \\
h_{2} \\
1
\end{array}\right],
$$

or in matrix form as

$$
\boldsymbol{E} \cdot \boldsymbol{P}=\boldsymbol{H},
$$

in which $\boldsymbol{E}$ represents the matrix of the celestial bodies positions in the celestial equator coordinate system, $\boldsymbol{P}$ represents the vector of the AVP in the Earth coordinate system, and $\boldsymbol{H}$ represents the vector of the observed altitudes of the celestial bodies in the celestial horizontal coordinate system. The above equation can be 
considered as a constitutive equation set of three different coordinate systems on the celestial sphere for celestial navigation.

In summary, using the matrix method to construct the needed equation is quite directly; however, the plane analytic geometrics should be used. It leads to complicated mathematical operations in solving process and it is nearly impossible to calculate the result only by means of a calculator [7, 13, 16, 17]. Therefore, coding the calculation procedure into a numerical program is usually necessary to obtain the AVP.

\section{DERIVATIONS OF GOVERNING EQUATIONS AND CONSTRUCTION OF COMPUTATION PROCEDURES}

In this section, the vector algebra will be used to formulate some basic equations, which are found to be the spherical triangle equations. Besides, based on the combined formulae for different conditions of celestial observation, the computation procedures are constructed to determine the AVP.

First of all, since the celestial equator coordinate system is the extension of the Earth coordinate system, the celestial sphere can be considered as a unit sphere. Therefore, from the viewpoint of the navigator, the position variables, the latitude and the longitude, described in the Earth coordinate system and the position variable, declination and Greenwich hour angle, described in the celestial equator coordinate system can replace the conventional (mathematical) spherical coordinate system. By doing so, the position vector for any point $P$ in the Cartesian coordinate system can be expressed as

$$
\begin{aligned}
\vec{P} & =(\cos L \cdot \cos \lambda, \cos L \cdot \sin \lambda, \sin L) \\
& =(\cos d \cdot \cos G H A, \cos d \cdot \sin G H A, \sin d),
\end{aligned}
$$

in which $L$ represents the latitude of the observer, $\lambda$ represents the longitude of the observer, $d$ represents the declination of the celestial body, and GHA represents the Greenwich hour angle of the celestial body.

Since the coordinate system has been decided, the sign convention of the latitude or the declination is: a positive value for the north, negative for the south. Then, the concept of the relative meridian is introduced and the Greenwich meridian is replaced as the local meridian for transformation of the coordinate system, as shown in Fig. 4. Therefore, the position vectors for the zenith, celestial body and elevated pole can be respectively expressed as

$$
\vec{X}=(\cos L, 0, \sin L),
$$

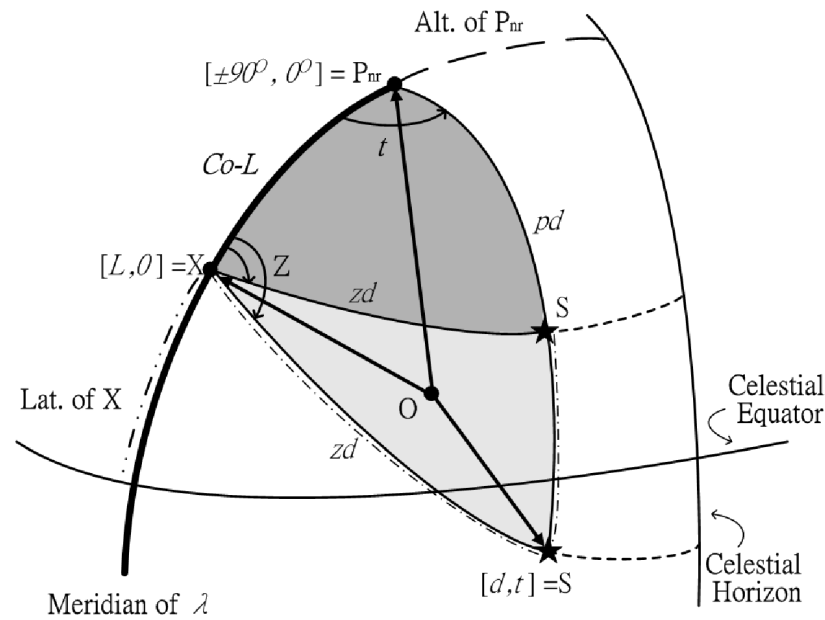

Fig. 4. The astronomical triangle in the combined celestial equator and celestial horizon systems of coordinates.

$$
\begin{aligned}
& \vec{S}=(\cos d \cdot \cos t, \cos d \cdot \sin t, \sin d), \\
& \vec{P}_{\mathrm{nr}}=(0,0, \pm 1)
\end{aligned}
$$

in which $t$ is the meridian angle and its value is determined by the difference of the longitude of the observer and the Greenwich hour angle of the celestial body. The sign convention is decided according to the conventional practice of the celestial navigation [3].

\section{Derivation of the basic equations}

By introducing the concept that the latitude of the observer is equal to the altitude of the elevated pole, the celestial equator coordinate system and the celestial horizontal coordinate system can be combined together; that is, the described position variables, altitude and azimuth angle, for the celestial horizontal coordinate system based on the observer can be set up on the celestial sphere. Hence, the astronomical triangle can be formed, and its three vertices, three sides and three angles are shown as Fig. 4.

\section{A. Equal altitude equation of celestial body}

In Fig. 4, the included angle, side of astronomical triangle, of the unit vectors, $\vec{X}$ and $\vec{S}$, is exactly the zenith distance, $z d$, and it is also called the co-altitude since the celestial body can only be observed upon the celestial horizontal plane. According to the geometric and algebraic definitions of the dot product of two vectors, one can have

$$
\vec{X} \cdot \vec{S}=1 \cdot 1 \cdot \cos (z d)=\sin H
$$

(Geometric definition) 
$=\cos L \cdot \cos d \cdot \cos t+\sin L \cdot \sin d$

(Algebraic definition),

and rearranging the above equation one has

$$
\sin H=\sin L \cdot \sin d+\cos L \cdot \cos d \cdot \cos t,
$$

in which $H$ represents the altitude of the celestial body. It should be note that Eq. (3) is the well-known cosine formula for side in spherical trigonometry. Since several formulae, such as the haversine formula, are derived from this equation, it has been recognized as the basic formula in celestial navigation $[2,11]$.

\section{B. Azimuth angle equation of celestial body}

For different given conditions there can have different azimuth angle equations of celestial body, the altitude azimuth equation, the time and altitude azimuth equation and the time azimuth equation, are derived, respectively, in the following.

a. The altitude azimuth equation

As shown in Fig. 4, the cosine formula for side in the spherical trigonometry can be expressed as

$$
\cos (p d)=\sin L \cdot \cos (z d)+\cos L \cdot \sin (z d) \cdot \cos Z,(4)
$$

in which $p d$ represents the polar distance and $Z$ represents the azimuth angle. Because $p d=90^{\circ} \mp d$ and $z d=$ $90^{\circ}-H$, Eq. (4) yields

$$
\sin d=\sin L \cdot \sin H+\cos L \cdot \cos H \cdot \cos Z
$$

Therefore, the azimuth angle can be obtained as

$$
\cos Z=\frac{\sin d-\sin L \cdot \sin H}{\cos L \cdot \cos H} .
$$

Eq. (6) is another form of the cosine formula for side in spherical trigonometry. When the altitude of the celestial body is given, the azimuth angle can be determined from the equation, which is thus called the altitude azimuth equation in celestial navigation $[2,11]$.

b. The time and altitude azimuth equation

As shown in Fig. 4, the azimuth angle is the included angle, angle of astronomical triangle, of the two unit vectors, $(\vec{X} \times \vec{S})$ and $\left(\vec{X} \times \vec{P}_{n r}\right)$. The geometric and algebraic meanings of the cross products of the two vectors can be expressed as

$$
\begin{aligned}
& \left\|\vec{X} \times \vec{S}|\times| \vec{X} \times \vec{P}_{n r}\right\| \\
& =|[\sin (z d) \cdot \sin (C o-L) \cdot \sin (Z)] \vec{X}| \\
& =\cos H \cdot \cos L \cdot \sin Z \text { (Geometric def inition) } \\
& =\left|\left[(\vec{X} \times \vec{S}) \cdot \vec{P}_{n r}\right] \vec{X}\right| \\
& =\cos L \cdot \cos d \cdot \sin t \text { (Algebratic definition) }
\end{aligned}
$$

and rearranging it yield

$$
\cos H \cdot \sin Z=\cos d \cdot \sin t
$$

Eq. (7) is the sine formula in spherical trigonometry and is also called the time and altitude azimuth equation in celestial navigation. Besides, a combination of Eqs. (3) and (7) is called the sin-cosine equations or the classic equations.

c. The time azimuth equation

Substituting Eqs. (3) and (7) in Eq. (5) yields

$$
\begin{aligned}
\sin d & =(\sin d \cdot \sin L+\cos d \cdot \cos L \cdot \cos t) \cdot \sin L \\
& +\left(\frac{\cos d \cdot \sin t}{\sin Z}\right) \cdot \cos L \cdot \cos Z
\end{aligned}
$$

Rearranging the above equation can yield

$$
\begin{aligned}
\sin d \cdot\left(1-\sin ^{2} L\right) & =(\cos d \cdot \cos L \cdot \cos t \cdot \cos L) \\
& +\cos d \cdot \sin t \cdot \cos L \cdot \cot Z
\end{aligned}
$$

By dividing $\cos d \cdot \cos L$ at two sides of the above equation simultaneously yields

$$
\tan d \cdot \cos L=\cos t \cdot \sin L+\sin t \cdot \cot Z
$$

Hence

$$
\tan Z=\frac{\sin t}{(\cos L \cdot \tan d)-(\sin L \cdot \cos t)} .
$$

Eq. (8) is the four parts equation of the spherical trigonometry. When the altitude is unknown, this equation can be used to obtain the azimuth to adjust the compass error for observation of the celestial body. Therefore, this equation is also called the time azimuth equation in celestial navigation $[2,11]$.

\section{Construction of the computation procedures}

Based on "do right things (effectiveness) rather than do things right (efficiency)", the computation 
procedures of the altitude of a single celestial body and the altitudes of two celestial bodies can be constructed by choosing different combinations of formulae to determine AVP effectively at different sight conditions.

\section{A. Condition of the altitude of a single celestial body}

a. The combined computation formulae of the intercept method

The intercept method is to choose an AP, at the nearby of the MPP and take it as the reference position to compute the altitude and the azimuth, respectively. The appropriate measure is to choose Eqs. (3) and (8) and one has

$$
\begin{aligned}
& \sin H_{C}=\sin L \cdot \sin d+\cos L \cdot \cos d \cdot \cos t, \\
& \tan Z_{C}=\frac{\sin t}{(\cos L \cdot \tan d)-(\sin L \cdot \cos t)},
\end{aligned}
$$

in which $H_{C}$ represent the computed altitude and $Z_{C}$ represents the computed azimuth angle.

b. The computation procedures to solve the LOP without intercept

In fact, Eqs. (9) and (10) are generally used to make the sight reduction tables for marine navigation, more specifically, the commonly used Pub. No. 229. The AP is originated for entering arguments of integral degrees in accordance with the inspection table. If the computation method is adopted, the choice of the initial reference positions, such as the DR position, the MPP, or the optimal EP, can be unconstrained. As mentioned in the previous section, the distance between the AP and the true vessel position should not exceed 30 nautical miles due to entering arguments of integrated degrees. Again, if the computation method is used, this impractical regulation can be released and the accuracy of the obtained AVP can be increased by the iteration method. From the viewpoint of computation, once the computed azimuth is obtained, the perpendicular intersection can be calculated by using the classic equations. Then, the computed azimuth line and the LOP can be plotted by considering the intersection as the reference point of the possible AVP. In other words, this scheme is a kind of computation methods which can plot the LOP without intercept. Hence, it is an improved approach for conventional intercept method. It's basic idea is illustrated in the following.

Eqs. (7) and (3) are chosen for plotting the LOP without intercept and they can further be expressed as

$$
\begin{aligned}
& \sin t=\frac{\cos H_{0} \cdot \sin Z_{C}}{\cos d}, \\
& \sin H_{0}=\sin L \cdot \sin d+\cos L \cdot \cos d \cdot \cos t
\end{aligned}
$$

in which $Z_{C}$ represents the computed azimuth angle and it can be obtained by using Eq.(10), and $H_{0}$ represents the observed altitudes. By using Eq. (11), the meridian angle can be obtained quickly and a comparison of the longitude of the initial reference position and the GP can yield the longitude of the possible AVP easily. Similarly, the latitude of the possible AVP can be obtained by using Eq. (12). Derivations of the trigonometric equation for the computation are presented in the following.

Dividing $d$ at two sides of Eq. (12) simultaneously can yield

$$
\frac{\sin H_{0}}{\sin d}=\sin L+\frac{\cos L \cdot \cos t}{\tan d} .
$$

Now, let

$$
\tan \theta=\frac{\cos t}{\tan d}
$$

Substitute Eq. (14) in Eq. (13), multiply $\cos \theta$ at both sides simultaneously and introduce the additional formula can yield

$$
\sin (L+\theta)=\frac{\sin H_{0} \cdot \cos \theta}{\sin d}
$$

Therefore, the computation procedures to solve the LOP without intercept can be summarized in the following.

Step 1. The computed azimuth angle $Z_{C}$ can be obtained by using Eq. (10).

Step 2. The longitude of the possible AVP can be obtained by using Eq. (11).

Step 3. The latitude of the possible AVP can be obtained by using Eqs. (14) and (15).

Step 4. By taking the possible AVP as the reference point and plotting the azimuth line according to the computed azimuth, the LOP can be determined from the line which is perpendicular to the azimuth line and passes through the reference point simultaneously. This step is also a graphic drawing work.

\section{B. Condition of the altitudes of two celestial bodies}

The condition of the altitude of two celestial bodies can be categorized into two cases. One is the case of observing the altitudes of two celestial bodies simultaneously or nearly simultaneously; the other one is the case of observing altitudes of the same or different celestial bodies at different time. For the latter case, the 
running fix concept is usually adopted and after the course, speed and the period of two observing times have been identified the latter case can be transferred into the former case when the rhumb line sailings in conjunction with the moving reference position, the GP of high-altitude observation or the AP of intercept method, is adopted. The reason is to obtain a celestial fix, each would have to be advanced or retired to the desired for the fix, making proper allowance for the travel of the ship during the intervening time [2, 11]. As shown in Fig. 5, since the observing altitudes and its GPs of two celestial bodies have been determined, the equal altitude equations of the two celestial bodies can be expressed in the following:

$$
\begin{aligned}
& \cos d_{1} \cdot \cos t_{1} \cdot \cos L+\sin d_{1} \cdot \sin L=\sin H_{1} \\
& \cos d_{2} \cdot \cos t_{2} \cdot \cos L+\sin d_{2} \cdot \sin L=\sin H_{2}
\end{aligned}
$$

in which $d_{1}, t_{1}, H_{1}$ and $d_{2}, t_{2}, H_{2}$ represent the declination, meridian angle and observed altitude of the celestial body $1, S_{1}$, and the celestial body $2, S_{2}$, respectively.

Now let $a_{1}=\cos d_{1}, b_{1}=\sin d_{1}, c_{1}=\sin H_{1}, a_{2}=$ $\cos d_{2}, b_{2}=\sin d_{2}$, and $c_{2}=\sin H_{2}$. From Eqs. (16) and (17), one has

$$
\begin{aligned}
& \cos L=\frac{b_{2} c_{1}-b_{1} c_{2}}{a_{1} b_{2} \cos t_{1}-a_{2} b_{1} \cos t_{2}}, \\
& \sin L=\frac{a_{1} c_{2} \cos t_{1}-a_{2} c_{1} \cos t_{2}}{a_{1} b_{2} \cos t_{1}-a_{2} b_{1} \cos t_{2}} .
\end{aligned}
$$

Basically, the celestial equator coordinate system can be considered as the extension of the Earth coordinate system. Since the two systems have been integrated in the celestial sphere and are further combined with the celestial horizontal coordinate system; based

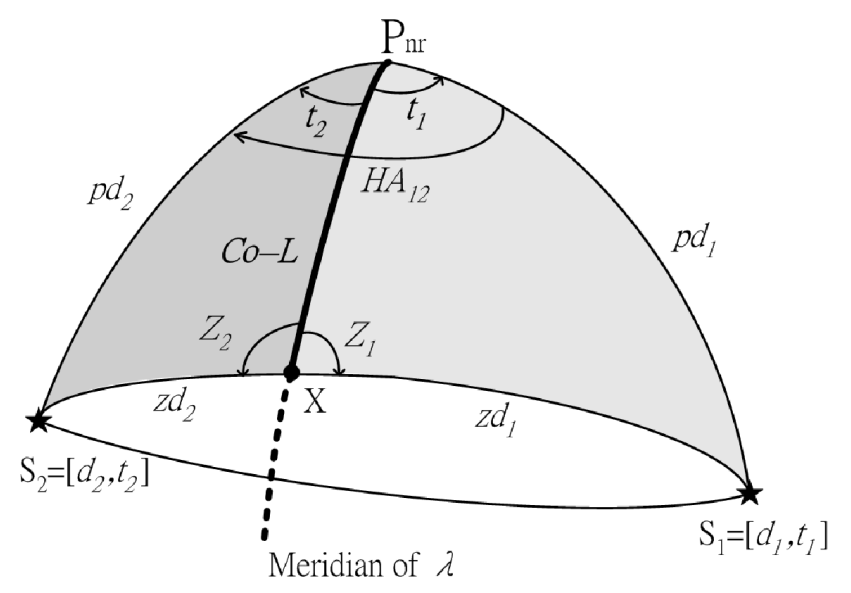

Fig. 5. An illustration of obtaining an astronomical vessel position by using the SEEM. on the concepts that the observer is exactly the zenith and the celestial sphere is a unit sphere, the length of the unit vector is equal to 1 in geometric definition, and the observed altitude of the zenith should be 90 degrees in celestial navigation, that means

$$
\cos ^{2} L+\sin ^{2} L=1
$$

Substituting Eqs. (18) and (19) in Eq. (20) and rearranging it, the relation of the meridian angles of the two celestial bodies in the combined coordinate system can be yielded as

$\left(A \cdot \cos t_{1}-B \cdot \cos t_{2}\right) \cdot\left(C \cdot \cos t_{1}-D \cdot \cos t_{2}\right)=E^{2}$,

in which

$$
\left.\begin{array}{l}
A=a_{1}\left(b_{2}-c_{2}\right)=\cos d_{1} \cdot\left(\sin d_{2}-\sin H_{2}\right) \\
B=a_{2}\left(b_{1}-c_{1}\right)=\cos d_{2} \cdot\left(\sin d_{1}-\sin H_{1}\right) \\
C=a_{1}\left(b_{2}+c_{2}\right)=\cos d_{1} \cdot\left(\sin d_{2}+\sin H_{2}\right) \\
D=a_{2}\left(b_{1}+c_{1}\right)=\cos d_{2} \cdot\left(\sin d_{1}+\sin H_{1}\right) \\
E=b_{2} c_{1}-b_{1} c_{2}=\sin d_{2} \cdot \sin H_{1}-\sin d_{1} \cdot \sin H_{2}
\end{array}\right\}
$$

Since now the celestial bodies can be observed simultaneously, the difference of meridian angles for the two celestial bodies can be expressed as (refer to Fig. 5)

$$
H A_{12}=t_{1} \sim t_{2}
$$

in which $H A_{12}$ denotes the difference of meridian angles from celestial body 1 to body 2 . Taking the cosine operation in Eq. (23) yields

$$
\cos t_{1}=p \cdot \cos t_{2}+q \cdot \sin t_{2}
$$

in which

$$
\left.\begin{array}{l}
p=\cos H A_{12} \\
q=\sin H A_{12}
\end{array}\right\} .
$$

Substituting Eq. (24) in Eq. (21) yields

$$
\begin{aligned}
& {\left[(A p-B) \cdot \cos t_{2}+A q \cdot \sin t_{2}\right] \cdot\left[(C p-D) \cdot \cos t_{2}\right.} \\
& \left.\quad+C q \cdot \sin t_{2}\right]=E^{2}
\end{aligned}
$$

To solve the meridian angle of celestial body $2, t_{2}$, from Eq. (26), let

$$
\tan \alpha=\frac{A p-B}{A q},
$$


in which

$$
\left.\begin{array}{l}
\sin \alpha=\frac{A p-B}{R} \\
\cos \alpha=\frac{A q}{R} \\
R= \pm \sqrt{(A p-B)^{2}+(A q)^{2}}
\end{array}\right\}
$$

and also let

$$
\tan \beta=\frac{C p-D}{C q}
$$

in which

$$
\left.\begin{array}{l}
\sin \beta=\frac{C p-D}{S} \\
\cos \beta=\frac{C q}{S} \\
S= \pm \sqrt{(C p-D)^{2}+(C q)^{2}}
\end{array}\right\}
$$

It should be noted that the sign convention of $R$ is the same as that of the multiply product of $A p-B$ and $A q$. Similarly, the sign convention of $\mathrm{S}$ is determined by that of the multiply product of $C p-D$ and $C q$. Substituting Eqs. (27) and (29) in Eq. (26) and introducing the additional formulae, one has

$$
\sin \left(t_{2}+\alpha\right) \cdot \sin \left(t_{2}+\beta\right)=\frac{E^{2}}{R S} .
$$

Introducing the products of trigonometric functions in Eq. (31) yields

$$
\cos \left(2 t_{2}+\alpha+\beta\right)=\cos (\alpha-\beta)-\frac{2 E^{2}}{R S}
$$

Now, $t_{2}$ can be obtained and reduced to the longitude of the AVP. By using Eq. (23), the meridian angle of the celestial body $1, t_{1}$, can be obtained. Therefore, the computation procedure of the SEEM can be summarized in the following.

Step 1. The preliminaries, $A, B, C, D, E, p, q, R$ and $S$, can be obtained by using Eqs. (22), (25), (28), and (30).

Step 2. The parameters, $\alpha$ and $\beta$, can be obtained from Eqs. (27) and (29).

Step 3. The meridian angle of celestial body $2, t_{2}$, can be obtained from Eq. (32) and can be further reduced to the longitude of the AVP, $\lambda$. Besides, the meridian angle of celestial body $1, t_{1}$, can be determined from Eq. (23).

Step 4. Repeating uses of Eqs. (14) and (15) for Eqs. (16) and (17), respectively, can determine the latitudes of the AVPs for celestial body 1 and celestial body 2 , respectively. Besides, the results can be checked with each other for validation.

\section{ILLUSTRATED EXAMPLES}

Two examples are used to validate the proposed improved approach for solving the LOP without intercept and the SEEM, respectively. Results are further compared with those of the intercept method commonly used in conjunction with the inspection tables (Pub. No. 229).

Example 1. A vessel is in the position of $D R L 39^{\circ} \mathrm{N}$, $\lambda 157^{\circ} 08.0^{\prime} \mathrm{W}$ at the Zone Time of $20-07-43$ to observe the Star Kochab with a sextant and to observe the Star Spica in the position of $D R L 39^{\circ} N, \lambda 157^{\circ} 10.0^{\prime} \mathrm{W}$ at the Zone Time of 20-11-26. The navigator records the needed information and further reduces it from the nautical almanac for sight reduction as shown in Table $1[2]$.

Required: The AVP can be determined in the following three approaches for sight reduction.

1. Using the intercept method together with the inspection table to solve the $A P, Z n$ and $a$, and plot the LOP. (Approach 1)

2. Treating DR as the initial reference position, using the computation method without intercept to solve the possible AVP, and plot the LOP. (Approach 2)

3. Using the SEEM to determine the AVP directly.

\section{Solution.}

1. The three elements, $A P, Z n$ and $a$, for plotting the LOPs from the inspection table and needed information are summarized in Table 2. They can be shown in the small area plotting sheet to plot the LOPs and determine the AVP, which is the intersection of the two LOPs as shown in Fig. 6.

2 . Use of the proposed improved approach without intercept can obtain the computed azimuth and possible AVP as the reference point. The procedures and results are summarized in Table 3 . Those results can be used to determine the AVP, as shown in Fig. 6.

3. Use of the SEEM can directly determine the AVP,

Table 1. The needed information for sight reduction in example 1

\begin{tabular}{cccl}
\hline Body & ZT & Ho & \multicolumn{1}{c}{ GP } \\
\hline Kochab & $20-07-43$ & $47^{\circ} 13.6^{\prime}$ & $\left(\begin{array}{l}74^{\circ} 10.6^{\prime} \mathrm{N} \\
103^{\circ} 43.0^{\prime} \mathrm{W}\end{array}\right.$ \\
Spica & $20-11-26$ & $32^{\circ} 28.7^{\prime}$ & $\begin{array}{l}11^{\circ} 08.4^{\prime} \mathrm{S} \\
126^{\circ} 05.7^{\prime} \mathrm{W}\end{array}$ \\
\hline
\end{tabular}

Source: [2] 
$L 39^{\circ} \mathrm{N}, 1156^{\circ} 21.7^{\prime} \mathrm{W}$, without plotting. The details are summarized in Table 4 and the result is shown in Fig. 6.

As shown in Fig. 6, although some errors may arise in the first two approaches due to graphical drawings and measures, results from the three approaches are nearly the same, and it shows that theories of the proposed computation approaches have been validated. Besides, they are also superior to the conventional intercept method from indices of calculation speed and plotting the LOP. Moreover, the proposed SEEM can determine the AVP directly without plotting as compared with the other two approaches.

Example 2. The 2004 DR position of a vessel is $L 41^{\circ} 34$. $8^{\prime} N, \lambda 017^{\circ} 00.5^{\prime} W$. At $20-03-58$, the star Capella is observed with a sextant. At 20-02-56, shortly before the above observation, a sight had been taken on another star, Alkaid. The navigator records the needed information and further reduces it from the nautical almanac for

Table 2. Three elements, $A P, Z n$ and $a$, for plotting the LOPs by using approach 1 in example 1

\begin{tabular}{|c|c|c|}
\hline Body & \multicolumn{2}{|c|}{ The three plotting elements of LOP } \\
\hline Kochab & $A P\left(\begin{array}{l}39^{\circ} \mathrm{N} \\
156^{\circ} 43.0^{\prime} \mathrm{W}\end{array}\right.$ & $\begin{array}{c}Z n=018.9^{\circ} \\
a=5.2^{\prime} \text { 'Toward }\end{array}$ \\
\hline Spica & $A P\left(\begin{array}{l}39^{\circ} \mathrm{N} \\
157^{\circ} 05.7^{\prime} \mathrm{W}\end{array}\right.$ & $\begin{array}{l}Z n=143.3^{\circ} \\
a=20.2^{\prime} \text { Toward }\end{array}$ \\
\hline
\end{tabular}

Source: [2]

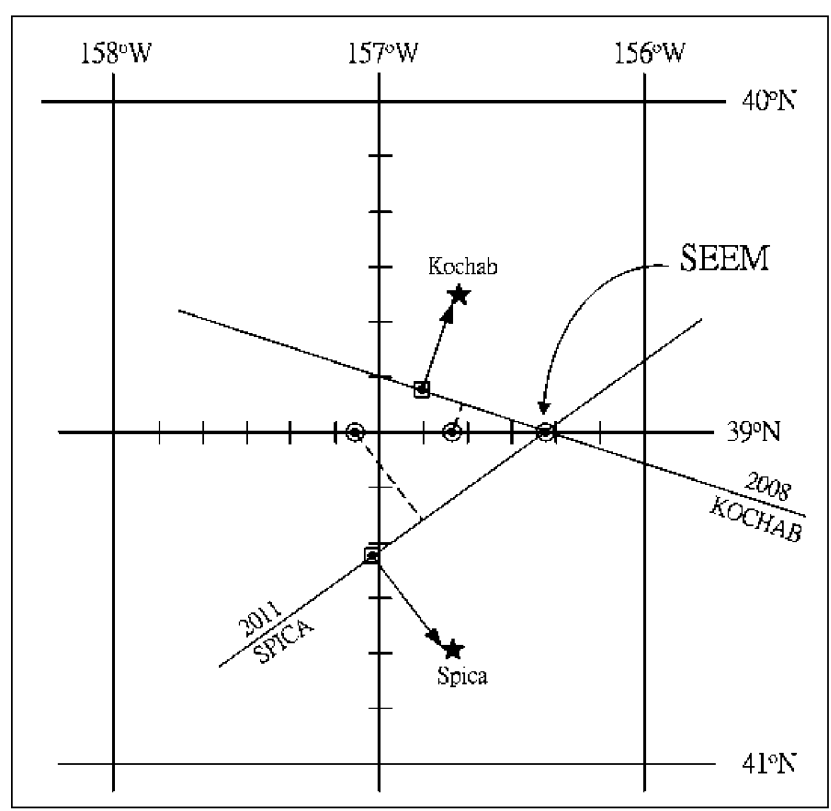

Fig. 6. A comparison of various methods for sight reduction in example 1. sight reduction as shown in Table 5 [11].

Required: The AVP can be determined using the three approaches for sight reduction.

\section{Solution.}

1. Results of $A P, Z n$ and $a$ are listed in Table 6 and the graphical AVP, $L 41^{\circ} 38.6^{\prime} N, \lambda 017^{\circ} 08.1^{\prime} W$ is shown in Fig. 7.

2. Results of the computed azimuth and possible AVP as the reference point are listed in Table 7 and the graphical AVP, $L 41^{\circ} 39.4^{\prime} N, \lambda 017^{\circ} 06.9^{\prime} \mathrm{W}$ is shown in Fig. 7.

3. Use of the SEEM can directly determine the AVP, $L 41^{\circ} 39.1^{\prime} \mathrm{N}, \lambda 017^{\circ} 07.3^{\prime} \mathrm{W}$, without plotting. Results and the procedures are listed in Table 8 and the computed AVP is shown in Fig. 7.

In Fig. 8, which shows computing results of the three approaches along the LOP of the star Capella in a larger scale of Fig. 7, it has been found that the computed AVPs are not the same. Therefore, the improved approach (approach 2) with the iteration method is proposed to validate the true AVP. The details of computing results are listed in Table 9. In Fig. 8, it shows that when using the AVPs obtained from approaches 1 and 2, respectively, as the initial values for iterations; both of them are approaching fast to the AVP

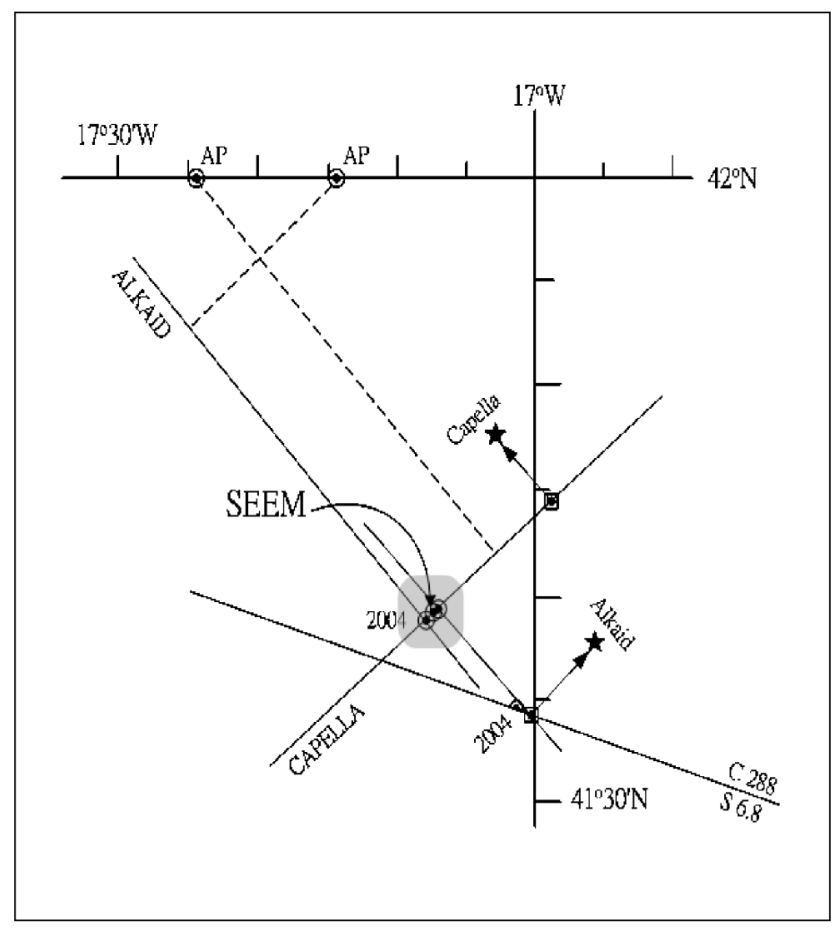

Fig. 7. A comparison of various methods for sight reduction in example 2. 
Table 3. The solving process of approach 2 for obtaining the LOPs in example1

\begin{tabular}{|c|c|c|c|c|}
\hline Process & Eqn. & Input & Output & Solution \\
\hline $\begin{array}{c}\text { (Kochab) } \\
1\end{array}$ & (10) & $\begin{array}{c}t=53^{\circ} 25.0^{\prime} E \text { (Est.) } \\
L=39^{\circ} \text { (DRL) } \\
d=74^{\circ} 10.6^{\prime} \text { (GPL) }\end{array}$ & $Z c=\mathrm{N} 18.73888561^{\circ} E$ & $\mathrm{Zn}=18.7^{\circ}$ \\
\hline 2 & (11) & $\begin{array}{c}H o=47^{\circ} 13.6^{\prime} \\
Z c=18.73888561^{\circ} \\
d=74^{\circ} 10.6^{\prime}\end{array}$ & $t=53.13957475^{\circ} \mathrm{E}$ & $\lambda=156^{\circ} 51.4^{\prime} W$ \\
\hline \multirow[t]{2}{*}{3} & (14) & $\begin{array}{l}t=53^{\circ} 08.4^{\prime} \\
d=74^{\circ} 10.6^{\prime}\end{array}$ & $\theta=9.648471827^{\circ}$ & \\
\hline & $(15)$ & $H o, \theta, d$ & $L+\theta=48.7782125^{\circ}$ & $L=39^{\circ} 07.8^{\prime} N$ \\
\hline $\begin{array}{c}\text { (Spica) } \\
1\end{array}$ & (10) & $\begin{array}{c}t=31^{\circ} 04.3^{\prime} E \text { (Est.) } \\
L=39^{\circ} \text { (DRL) } \\
d=-11^{\circ} 08.4^{\prime}(\mathrm{GPL})\end{array}$ & $\begin{array}{l}Z c=-36.71403879^{\circ} \\
=N 143.28596121^{\circ} E(*)\end{array}$ & $Z n=143.3^{\circ}$ \\
\hline 2 & (11) & $\begin{array}{c}H o=32^{\circ} 28.7^{\prime} \\
Z c=143.28596121^{\circ} \\
d=-11^{\circ} 08.4^{\prime}\end{array}$ & $t=30.93089691^{\circ} \mathrm{E}$ & $\lambda=157^{\circ} 01.6^{\prime} W$ \\
\hline \multirow[t]{2}{*}{3} & (14) & $\begin{aligned} t & =30^{\circ} 55.9^{\prime} \\
d & =-11^{\circ} 08.4^{\prime}\end{aligned}$ & $\theta=-77.07085715^{\circ}$ & \\
\hline & (15) & $H o, \theta, d$ & $L+\theta=-38.45190368^{\circ}$ & $L=38^{\circ} 37.1^{\prime} N$ \\
\hline \multirow{2}{*}{ Answer } & Kochab: & $\left(\begin{array}{l}39^{\circ} 07.8^{\prime} N \\
156^{\circ} 51.4^{\prime} W\end{array}, Z n=18.7^{\circ}\right.$ & & \\
\hline & Spica: & $\begin{array}{l}38^{\circ} 37.1^{\prime} \mathrm{N} \\
157^{\circ} 01.6^{\prime} W\end{array}, Z n=143.3^{\circ}$ & & \\
\hline
\end{tabular}

* Since $\tan (-\theta)=\tan \left(180^{\circ}-\theta\right)$ therefore, $(-\theta)$ is replaced as $\left(180^{\circ}-\theta\right)$.

Table 4. The solving process of the SEEM for obtaining the astronomical vessel position in example 1

\begin{tabular}{|c|c|c|c|c|}
\hline Process & Eqn. & Input & Output & Solution \\
\hline preliminary & $\begin{array}{l}(22) \\
(25) \\
(28) \\
(30)\end{array}$ & $\begin{array}{c}d_{1}=74^{\circ} 10.6^{\prime} \\
d_{2}=-11^{\circ} 08.4^{\prime} \\
H_{1}=47^{\circ} 13.6^{\prime} \\
H_{2}=32^{\circ} 28.7^{\prime} \\
H A_{12}=22^{\circ} 22.7^{\prime} W\end{array}$ & $\begin{array}{l}A=-0.199101781 \\
B=0.233763897 \\
C=0.093737476 \\
D=1.664194158 \\
E=-0.658455667 \\
p=0.924690071 \\
q=-0.380720728 \\
R=-0.414855393 \\
S=1.577919672\end{array}$ & \\
\hline 1 & $\begin{array}{l}(27) \\
(29)\end{array}$ & $\begin{array}{l}A, B, p, q \\
C, D, p, q\end{array}$ & $\begin{array}{l}\alpha=-79.47179607^{\circ} \\
\beta=88.70403119^{\circ}\end{array}$ & \\
\hline \multirow[t]{2}{*}{2} & (32) & $\begin{array}{c}E, R, S, \text { and } \\
\cos (\alpha-\beta) \\
=-0.978781026\end{array}$ & $\begin{array}{l}2 t_{2}+\alpha+\beta \\
=69.76509369^{\circ} \\
t_{2}=30.26642929^{\circ} \\
=30^{\circ} 16.0^{\prime} E\end{array}$ & $\lambda=156^{\circ} 21.7^{\prime} W$ \\
\hline & (23) & $H A_{12}, t_{2}$ & $t_{1}=52^{\circ} 38.7^{\prime} E$ & \\
\hline 3 & $\begin{array}{l}(14) \\
(15)\end{array}$ & $\begin{array}{c}t_{1}, d_{1} \\
H_{1}, \theta, d_{1}\end{array}$ & $\begin{array}{l}\theta=9.757174353^{\circ} \\
L+\theta=48.75700565^{\circ}\end{array}$ & $\begin{array}{c}L=38.9998313^{\circ} \\
=39^{\circ} \mathrm{N}\end{array}$ \\
\hline Check & $\begin{array}{l}(14) \\
(15)\end{array}$ & $\begin{array}{c}t_{2}, d_{2} \\
H_{2}, \theta, d_{2}\end{array}$ & $\begin{array}{l}\theta=-77.15635503^{\circ} \\
L+\theta=-38.15671934^{\circ}\end{array}$ & $\begin{array}{c}L=38.99963569^{\circ} \\
=39^{\circ} \mathrm{N}\end{array}$ \\
\hline
\end{tabular}

Answer: Astronomical Vessel Position: $L=39^{\circ} \mathrm{N}, \lambda=156^{\circ} 21.7^{\prime} \mathrm{W}$ 
Table 5. The needed information for sight reduction in example 2

\begin{tabular}{|c|c|c|c|}
\hline Body & ZT & Ho & GP \\
\hline Capella & $20-03-58$ & $15^{\circ} 19.3^{\prime}$ & $\left(\begin{array}{l}45^{\circ} 58.4^{\prime} \mathrm{N} \\
131^{\circ} 24.8^{\prime} W\end{array}\right.$ \\
\hline Alkaid & $20-02-56$ & $77^{\circ} 34.9^{\prime}$ & $\left(\begin{array}{l}49^{\circ} 25.7^{\prime} \mathrm{N} \\
003^{\circ} 14.2^{\prime} \mathrm{W}\end{array}\right.$ \\
\hline
\end{tabular}

Source: [11]
Table 6. Three elements, $A P, Z n$ and $a$, for plotting the LOPs by using approach 1 in example 2

\begin{tabular}{|c|c|c|}
\hline Body & The three plottin & elements of LOP \\
\hline Capella & $A P\left(\begin{array}{l}42^{\circ} \mathrm{N} \\
017^{\circ} 24.8^{\prime} W\end{array}\right.$ & $\begin{array}{c}Z n=318.8^{\circ} \\
a=24.2^{\prime} \text { Away }\end{array}$ \\
\hline Alkaid & $A P\left(\begin{array}{l}42^{\circ} N \\
017^{\circ} 14.2^{\prime} W\end{array}\right.$ & $\begin{array}{c}Z n=047.9^{\circ} \\
a=10.4^{\prime} \text { Away }\end{array}$ \\
\hline
\end{tabular}

Source: [11]

Table 7. The solving process of approach 2 for obtaining the LOPs in example 2.

\begin{tabular}{|c|c|c|c|c|}
\hline Process & Eqn. & Input & Output & Solution \\
\hline $\begin{array}{c}\text { (Capella) } \\
1\end{array}$ & (10) & $\begin{array}{c}t=114^{\circ} 24.3^{\prime} W \text { (Est.) } \\
L=41^{\circ} 34.8^{\prime} \text { (DRL) } \\
d=45^{\circ} 58.4^{\prime}(\text { GPL) }\end{array}$ & $Z c=\mathrm{N} 40.98587018^{\circ} \mathrm{W}$ & $Z n=319^{\circ}$ \\
\hline 2 & (11) & $\begin{array}{c}H o=15^{\circ} 19.3^{\prime} \\
Z c=40.98587018^{\circ} \\
d=45^{\circ} 58.4^{\prime}\end{array}$ & $\begin{array}{l}\mathrm{t}=65.52879657^{\circ} \text { or } \\
114.47120343^{\circ} \mathrm{W}(*)\end{array}$ & $\lambda=016^{\circ} 56.5^{\prime} \mathrm{W}$ \\
\hline \multirow[t]{2}{*}{3} & (14) & $\begin{array}{c}t=114^{\circ} 28.3^{\prime} \\
d=45^{\circ} 58.4^{\prime}\end{array}$ & $\theta=-21.82130093^{\circ}$ & \\
\hline & (15) & $H o, \theta, d$ & $L+\theta=19.94797852^{\circ}$ & $L=41^{\circ} 46.2^{\prime} \mathrm{N}$ \\
\hline $\begin{array}{c}\text { (Alkaid) } \\
1\end{array}$ & (10) & $\begin{array}{l}t=13^{\circ} 46.3^{\prime} E \text { (Est.) } \\
L=41^{\circ} 34.8^{\prime} \text { (DRL) } \\
d=49^{\circ} 25.7^{\prime}(\mathrm{GPL})\end{array}$ & $Z c=N 46.10682304^{\circ} E$ & $Z n=46.1^{\circ}$ \\
\hline 2 & (11) & $\begin{array}{c}H o=77^{\circ} 34.9^{\prime} \\
Z c=46.10682304^{\circ} \\
d=49^{\circ} 25.7^{\prime}\end{array}$ & $t=13.78447652^{\circ} \mathrm{E}$ & $\lambda=0.17^{\circ} 00.3^{\prime} \mathrm{W}$ \\
\hline \multirow[t]{2}{*}{3} & (14) & $\begin{array}{c}t=13^{\circ} 47.1^{\prime} E \\
d=49^{\circ} 25.7^{\prime}\end{array}$ & $\theta=39.74635188^{\circ}$ & \\
\hline & (15) & $H o, \theta, d$ & $L+\theta=81.32013587^{\circ}$ & $L=41^{\circ} 34.4^{\prime} N$ \\
\hline \multirow{2}{*}{ Answer } & Capella: & $\left(\begin{array}{l}41^{\circ} 46.2^{\prime} N \\
016^{\circ} 56.5^{\prime} W\end{array}, Z n=319^{\circ}\right.$ & & \\
\hline & Alkaid: & $\left(\begin{array}{l}41^{\circ} 34.4^{\prime} N \\
017^{\circ} 00.3^{\prime} W\end{array}, Z n=46.1^{\circ}\right.$ & & \\
\hline
\end{tabular}

$*$ Since $\sin \theta=\sin \left(180^{\circ}-\theta\right)$, either $\theta$ or $\left(180^{\circ}-\theta\right)$ can be chosen according to the estimated $t$.

obtained by using the SEEM. It proves that the SEEM is more accurate than the other two approaches. Besides, it is more versatile than the other two approaches especially for higher altitude observation conditions due to its theoretical background. Moreover, the SEEM can compute the AVP effectively without graphic procedures. In Fig. 8, it also has been found that the practical measured distance between the AVPs from approach 1 and the SEEM are over 0.5 nautical mile, this significant difference shows that there exist curvature errors due to the replacement of the COP by the LOP at the higher altitude of the star Alkaid in the intercept method. On the other hand, when the improved approach is adopted in conjunction with the iteration method, the accurate AVP can also be obtained by the direct computation without considering the two assumptions of the intercept method as shown in Fig. 8 and Table 9.

\section{CONCLUSIONS}

In this paper, two computation approaches based on the fixed coordinate system and the relative meridian concept have been developed to solve the AVP problem. 
Table 8. The solving process of the SEEM for obtaining the astronomical vessel position in example 2

\begin{tabular}{|c|c|c|c|c|}
\hline Process & Eqn. & Input & Output & Solution \\
\hline preliminary & $\begin{array}{l}(22) \\
(25) \\
(28) \\
(30)\end{array}$ & $\begin{aligned} d_{1} & =45^{\circ} 58.4^{\prime} \\
d_{2} & =49^{\circ} 25.7^{\prime} \\
H_{1} & =15^{\circ} 19.3^{\prime} \\
H_{2} & =77^{\circ} 34.9^{\prime} \\
H A_{12} & =128^{\circ} 10.6^{\prime} E\end{aligned}$ & $\begin{array}{l}A=-0.1508207907 \\
B=0.2957874168 \\
C=1.206644605 \\
D=0.6395072223 \\
E=-0.5014807812 \\
p=-0.618088309 \\
q=0.7861086708 \\
R=0.234712942 \\
S=-1.678947942\end{array}$ & \\
\hline 1 & $\begin{array}{l}(27) \\
(29)\end{array}$ & $\begin{array}{l}A, B, p, q \\
C, D, p, q\end{array}$ & $\begin{array}{l}\alpha=59.65973955^{\circ} \\
\beta=-55.59985116^{\circ}\end{array}$ & \\
\hline 2 & (32) & $\begin{array}{c}E, R, S, \text { and } \\
\cos (\alpha-\beta) \\
=-0.4267201302\end{array}$ & $\begin{array}{l}2 t_{2}+\alpha+\beta \\
=31.83031073^{\circ} \\
t_{2}=13.88521117^{\circ} \\
=13^{\circ} 53.1^{\prime} \mathrm{E}\end{array}$ & $\lambda=017^{\circ} 07.3^{\prime} W$ \\
\hline & $(23)$ & $H A_{12}, t_{2}$ & $t_{1}=114^{\circ} 17.5^{\prime} \mathrm{W}$ & \\
\hline 3 & $\begin{array}{l}(14) \\
(15)\end{array}$ & $\begin{array}{c}t_{1}, d_{1} \\
H_{1}, \theta, d_{1}\end{array}$ & $\begin{array}{l}\theta=-21.68459739^{\circ} \\
L+\theta=19.96778674^{\circ}\end{array}$ & $\begin{aligned} L= & 41.65238413^{\circ} \\
& =41^{\circ} 39.1^{\prime} \mathrm{N}\end{aligned}$ \\
\hline Check & $\begin{array}{l}(14) \\
(15)\end{array}$ & $\begin{array}{c}t_{2}, d_{2} \\
H_{2}, \theta, d_{2}\end{array}$ & $\begin{array}{l}\theta=39.73424525^{\circ} \\
L+\theta=81.38632549^{\circ}\end{array}$ & $\begin{aligned} L= & 41.65208024^{\circ} \\
& =41^{\circ} 39.1^{\prime} \mathrm{N}\end{aligned}$ \\
\hline
\end{tabular}

Answer: Astronomical Vessel Position: $L=41^{\circ} 39.1^{\prime} N, \lambda=017^{\circ} 07.3^{\prime} \mathrm{W}$

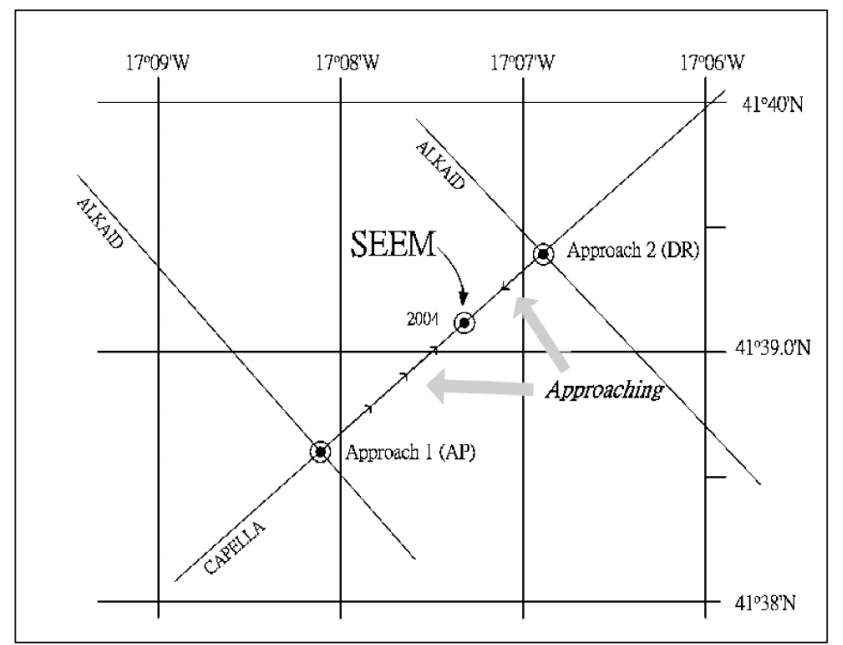

Fig. 8. Obtained astronomical vessel positions by using various methods in a larger scale for example 2.

Both of the two approaches adopt the vector algebra to construct the governing equations and thus simplified the computing procedures as compared with the conventional intercept method. Two available examples are included to validate the proposed two approaches. It is shown that the proposed approaches are not only more accurate than the conventional one but also more versatile especially when the higher altitude observation conditions are encountered. Besides, the proposed SEEM also shows its superiority over the other two approaches because it can determine the AVP directly without graphical procedures.

\section{REFERENCES}

1. A'Hearn, M.F. and Rossano, G.S., "Two Body Fixes by Calculator," Navigation: J. Inst. Naviga., Vol. 24, No. 1, pp. 59-66 (1977).

2. Bowditch, N., American Practical Navigator, DMAH/ TC, Washington (1984 and 2002).

3. Chen, C.L., Hsu, T.P., and Chang, J.R., “A Novel Approach to the Great Circle Sailing: The Great Circle Equation," Submitted to the Journal of Navigation (2003).

4. Chiesa, A. and Chiesa, R., "A Mathematical Method of Obtaining an Astronomical Vessel Position," Navigation, Vol. 43, pp. 125-129 (1990).

5. Clough-Smith, J.H., An Introduction to Spherical Trigonometry, Brown, Son and Ferguson, Ltd., Glasgow (1966). 
Table 9. The solving process of approach 2 in conjunction with the iteration method to determine astronomical vessel position

\begin{tabular}{|c|c|c|c|c|}
\hline \multirow[b]{2}{*}{ Iteration } & \multirow{2}{*}{$\begin{array}{l}\text { Reference } \\
\text { point }\end{array}$} & \multicolumn{2}{|c|}{ Body } & \multirow[b]{2}{*}{ Intersection } \\
\hline & & Capella & Alkaid & \\
\hline (Approach 1) & $A P, Z n, a$ & $\left(\begin{array}{ll}42^{\circ} \mathrm{N} & Z_{n}=318.8^{\circ} \\
017^{\circ} 24.8^{\prime} \mathrm{W} & a=24.2^{\prime} \mathrm{A}\end{array}\right.$ & $\left(\begin{array}{ll}42^{\circ} \mathrm{N} & Z_{n}=047.9^{\circ} \\
017^{\circ} 14.2^{\prime} \mathrm{W} & a=10.4^{\prime} \mathrm{A}\end{array}\right.$ & $\left(\begin{array}{l}41^{\circ} 38.6^{\prime} N \\
017^{\circ} 08.1^{\prime} W\end{array}\right.$ \\
\hline 1 & $\left(\begin{array}{l}41^{\circ} 38.6^{\prime} N \\
017^{\circ} 08.1^{\prime} W\end{array}\right.$ & $\left(\begin{array}{l}41^{\circ} 38.6^{\prime} N \\
017^{\circ} 08.1^{\prime} W\end{array}, Z_{n}=318.9^{\circ}\right.$ & $\left(\begin{array}{l}41^{\circ} 39.0^{\prime} N \\
017^{\circ} 07.2^{\prime} W\end{array}, Z_{n}=46.5^{\circ}\right.$ & $\left(\begin{array}{l}41^{\circ} 39.2^{\prime} \mathrm{N} \\
017^{\circ} 07.4^{\prime} W\end{array}\right.$ \\
\hline 2 & $\left(\begin{array}{l}41^{\circ} 39.2^{\prime} N \\
017^{\circ} 07.4^{\prime} W\end{array}\right.$ & $\left(\begin{array}{l}41^{\circ} 39.0^{\prime} N \\
017^{\circ} 07.5^{\prime} W\end{array}, Z_{n}=318.9^{\circ}\right.$ & $\left(\begin{array}{l}41^{\circ} 39.2^{\prime} \mathrm{N} \\
017^{\circ} 07.4^{\prime} W\end{array}, Z_{n}=46.5^{\circ}\right.$ & $\left(\begin{array}{l}41^{\circ} 39.2^{\prime} \mathrm{N} \\
017^{\circ} 07.3^{\prime} W\end{array}\right.$ \\
\hline 3 & $\left(\begin{array}{l}41^{\circ} 39.2^{\prime} \mathrm{N} \\
017^{\circ} 07.3^{\prime} W\end{array}\right.$ & $\left(\begin{array}{l}41^{\circ} 39.1^{\prime} N \\
017^{\circ} 07.3^{\prime} W\end{array}, Z_{n}=318.9^{\circ}\right.$ & $\left(\begin{array}{l}41^{\circ} 39.2^{\prime} N \\
017^{\circ} 07.4^{\prime} W\end{array}, Z_{n}=46.5^{\circ}\right.$ & $\left(\begin{array}{l}41^{\circ} 39.1^{\prime} N \\
017^{\circ} 07.3^{\prime} W\end{array}\right.$ \\
\hline 4 & $\left(\begin{array}{l}41^{\circ} 39.1^{\prime} \mathrm{N} \\
017^{\circ} 07.3^{\prime} \mathrm{W}\end{array}\right.$ & $\left(\begin{array}{l}41^{\circ} 39.1^{\prime} N \\
017^{\circ} 07.3^{\prime} W\end{array}, Z_{n}=318.9^{\circ}\right.$ & $\left(\begin{array}{l}41^{\circ} 39.2^{\prime} N \\
017^{\circ} 07.3^{\prime} W\end{array}, Z_{n}=46.5^{\circ}\right.$ & $\left(\begin{array}{l}41^{\circ} 39.1^{\prime} N \\
017^{\circ} 07.3^{\prime} W\end{array}\right.$ \\
\hline
\end{tabular}

Answer: Astronomical Vessel Position: $L=41^{\circ} 39.1^{\prime} \mathrm{N}, \lambda=017^{\circ} 07.3^{\prime} \mathrm{W}$

$\begin{array}{ccccc}\text { (Approach 2) } & \mathrm{DR}\left(\begin{array}{l}41^{\circ} 34.8^{\prime} N \\ 017^{\circ} 00.5^{\prime} W\end{array}\right. & \begin{array}{l}41^{\circ} 46.2^{\prime} N \\ 016^{\circ} 56.5^{\prime} W\end{array}, Z_{n}=319^{\circ} & \left(\begin{array}{l}41^{\circ} 34.4^{\prime} N \\ 017^{\circ} 00.3^{\prime} W\end{array}, Z_{n}=46.1^{\circ}\right. & \left(\begin{array}{l}41^{\circ} 39.4^{\prime} N \\ 017^{\circ} 06.9^{\prime} W\end{array}\right. \\ 1 & \left(\begin{array}{l}41^{\circ} 39.4^{\prime} N \\ 017^{\circ} 06.9^{\prime} W\end{array}\right. & \begin{array}{l}41^{\circ} 39.4^{\prime} N \\ 017^{\circ} 06.9^{\prime} W\end{array}, Z_{n}=318.9^{\circ} & \left(\begin{array}{l}41^{\circ} 39.2^{\prime} N \\ 017^{\circ} 07.4^{\prime} W\end{array}, Z_{n}=46.5^{\circ}\right. & \left(\begin{array}{l}41^{\circ} 39.1^{\prime} N \\ 017^{\circ} 07.3^{\prime} W\end{array}\right. \\ 2 & \left(\begin{array}{l}41^{\circ} 39.1^{\prime} N \\ 017^{\circ} 07.3^{\prime} W\end{array}\right. & \begin{array}{l}41^{\circ} 39.1^{\prime} N \\ 017^{\circ} 07.3^{\prime} W\end{array}, Z_{n}=318.9^{\circ} & \begin{array}{l}41^{\circ} 39.1^{\prime} N \\ 017^{\circ} 07.3^{\prime} W\end{array}, Z_{n}=46.5^{\circ} & \begin{array}{l}41^{\circ} 39.1^{\prime} N \\ 017^{\circ} 07.3^{\prime} W\end{array}\end{array}$

Answer: Astronomical Vessel Position: $L=47^{\circ} 39.1^{\prime} \mathrm{N}, \lambda=017^{\circ} 07.3^{\prime} \mathrm{W}$

6. Dewit, C., "Optimal Estimation of a Multi-Star Fix," Navigation: J. Inst. Naviga., Vol. 21, No. 4, pp. 320-325 (1974).

7. Dewit, C., "Some Remarks on Sight Reduction with Matrices," Navigation: J. Inst. Naviga., Vol. 26, No. 3, pp. 252-253 (1979).

8. IMO, International Convention on Standards of Training, Certification and Watchkeeping for Seafarers, 1978, as amended in 1995 (1995).

9. Kotlaric, S., "K-12 Method by Calculator: A Single Program For All Celestial Fixes, Directly or By Position Lines," Navigation: J. Inst. Naviga., Vol. 28, No. 1, pp. 44-51 (1981).

10. Kotlaric, S., "New Short Method Table (K11) for Direct Finding of a Two-Star Fix Without Use of Altitude Difference Method," Navigation: J. Inst. Naviga., Vol. 18, No. 4, pp. 440-449 (1971).

11. Maloney, E.S., Dutton's Navigation and Piloting, Naval Institute Press, Annapolis, Maryland (1985).
12. Pepperday, M., "The Two-Body Problem At Sea," Navigation, Vol. 45, pp. 138-142 (1992).

13. Robin-Jouan, Y., "The Method of Coplanar Vertices for Astronomical Positioning: Present Applications and Future Extensions," Navigation: J. Inst. Naviga., Vol. 46, No. 4, pp. 235-248 (1999).

14. Severance, R.W., "Overdetermined Celestial Fix by Iteration," Navigation: J. Inst. Naviga., Vol. 36, No. 4, pp. 373-378 (1989).

15. Sobel, D., Longitude: The True Story of a Lone Genius Who Solved the Greatest Scientific Problem of His Time, Penguin Books, Science History, London and New York (1996).

16. Van Allen, J.A., "An Analytical Solution of the Two Star Sight Problem of Celestial Navigation," Navigation: $J$. Inst. Naviga., Vol. 28, No. 1, pp. 40-43 (1981).

17. Watkins, R. and Janiczek, P.M., "Sight Reduction with Matrices," Navigation: J. Inst. Naviga., Vol. 25, No. 4, pp. 447-448 (1978). 